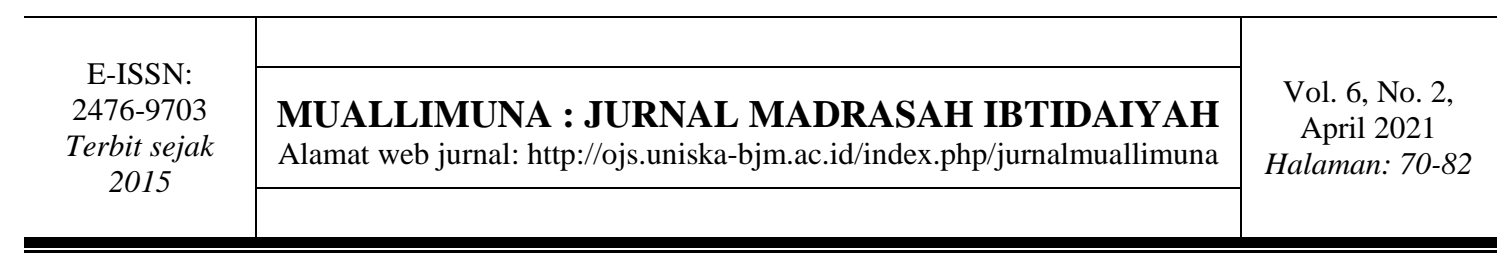

\title{
RANCANGAN LEMBAR KERJA MATEMATIKA SD/MI BERBASIS ISLAMIC ENVIRONMENTAL ETHICS
}

\author{
Luluk Mauluah $^{1}$, Marsigit ${ }^{2}$, Muhammad Nur Wangid ${ }^{3}$ \\ ${ }^{123}$ Program Doktoral Pendidikan Dasar, Universitas Negeri Yogyakarta \\ 1.mauluah@gmail.com, ${ }^{2}$ marsigitina@uny.ac.id, ${ }^{3}$ m_nurwangid@uny.ac.id
}

\begin{abstract}
Abstrak: Pembelajaran matematika di SD perlu memperkenalkan ketajaman rasa peduli terhadap lingkungan. Sekaligus pembelajaran di madrasah perlu mengenalkan nilai-nilai Islam untuk siswa MI bahwa merawat lingkungan merupakan amal yang saleh. Dengan alasan ini, maka dirancang Lembar Kerja pembelajaran matematika untuk kelas 1 SD/MI berbasis Islamic Environmental Ethics (IEE). Islamic Environmental Ethics memuat kaidah, bagaimana sebaiknya umat Islam memperlakukan tanaman, hewan, air, udara dan bumi. Penelitian pengembangan ini baru menempuh tahap Define dan Design, belum sampai ke tahap Develop dan Disseminate. Lembar Kerja yang dirancang memuat komponen-komponen berikut: Kompetensi Dasar, Indikator, Ayat Alqur'an, Hadits, Gambar-gambar, Aktifitas-aktifitas, kolom SAFETY dan Motivasi. Aktifitas yang dilakukan dalam Lembar kerja, menggunakan media di lingkungan peserta didik yaitu tanaman, bebatuan maupun biji-bijian.
\end{abstract}

Kata Kunci: Lembar kerja, Islamic Environmental Ethics, pembelajaran matematika, SD/MI

\section{DESIGNING ELEMENTARY STUDENT MATH WORKSHEET BASED ON ISLAMIC ENVIRONMENTAL ETHICS}

Abstract: Mathematics learning in elementary school needs to introduce a sharp sense of care for the environment. As well as learning in madrasas, it is necessary to introduce Islamic values to MI students that caring for the environment is a pious charity. For this reason, a mathematics learning worksheet for grade 1 SD / MI based on Islamic Environmental Ethics (IEE) was designed. Islamic Environmental Ethics contains rules, how should Muslims treat plants, animals, water, air and earth. This development research has only gone through the Define and Design stages, not yet at the Develop and Disseminate stages. The worksheets are designed to contain the following components: Basic Competencies, Indicators, Alquran verses, Hadith, Pictures, Activities, SAFETY columns and Motivation. Activities carried out in the worksheet, using media in the environment of students, namely plants, rocks and seeds.

Keywords: Worksheet, Islamic Environmental Ethics, mathematics learning, elementary school, madrasa

\section{PENDAHULUAN}

Kehidupan era post truth (Keyes, 2004) membutuhkan keahlian manusia, untuk dapat memilah, memilih, dan menggunakan sesuatu yang esensi dan substansi. Mempelajari ilmu, tak hanya untuk ilmu itu sendiri terapi harus memuat unsur 
kebermanfaatan. Bagaimana menjadi pendidik sejati, yang tidak hanya mengajarkan materi, tetapi juga mengajarkan nilai-nilai etika, ketuhanan, kebaikan menjadi hal yang sangat perlu untuk dilaksanakan.

Dengan semakin kompleksnya permasalahan pendidikan, permasalahan kelestarian lingkungan, yang dihadapi pada dekade akhir-akhir ini (Constanza, etal 2014), para praktisi dan ilmuwan terdorong, untuk semakin berpikir komprehensif dalam memandang berbagai persoalan. Pendekatan monodisiplin yang pada era-era sebelumnya menjadi ide saja, sekarang mulai bergeser untuk dikembang-terapkan. Pendekatan interdisiplin, multidisiplin dan transdisiplin dalam pembelajaran dan penelitian mulai didorong untuk diaplikasikan (Abdullah, 2021) Hal ini disebabkan karena, semakin rumitnya permasalahan yang dihadapi manusia, maka perlu cakupan pandangan yang lebih luas dari berbagai perspektif bidang ilmu, sehingga diharapkan dengan berbagai sudut pandang atau disiplin, maka dapat mempercepat diperolehnya solusi dari suatu masalah yang dihadapi. Sayangnya, belum semua sumber belajar di sekolah dasar maupun madrasah memfasilitasi hal ini.

Termasuk dalam penyelenggaraan pendidikan, khususnya pada pembelajaran matematika, juga memerlukan pandangan yang lebih luas dalam melaksanakannya. Pembelajaran matematika era post truth hendaknya sesuai dengan Permendikbud nomor 22 tahun 2016, yaitu mencakup capaian pembelajaran tidak hanya pengetahuan, tetapi juga ketrampilan dan sikap. Walaupun inovasi dan pengembangan terus diupayakan, tidak dapat dipungkiri, permasalahan-permasalahan dalam pembelajaran matematika masih selalu muncul. Baik itu mengenai model pembelajaran, proses pelaksanaan pembelajaran, strategi (Calkins, Grannan \& Siefken 2020), pemahaman siswa, motivasi siswa, maupun kemampuan guru.

Juga mengenai penyediaan bahan ajar yang cocok (Melvinasari, M. \& Suparman, S.2019); (Maskur, Permatasari \& Rakhmawati:2020) serta media dan peraga yang baik. Penggunaan lembar kerja yang bermakna (meaningful) juga perlu dikembangkan (Garcia, 2017); (Murtikusuma, Oktavianingtyas, Putri, Krisnawati, \& Fausi 2019) Hal ini disebabkan oleh banyaknya guru yang hanya menggunakan begitu saja LKS yang ada tanpa dikaji kesesuaiannya dengan kondisi dan kebutuhan sekolah/madrasah (Kholil \& Usriyah, 2019)

Penyelenggaraan pembelajaran matematika SD di lembaga pendidikan Islam mempunyai tanggung jawab tersendiri untuk senantiasa mempromosikan nilai-nilai Islam. Sangat banyak perintah dalam Alqur'an dan hadits agar umat manusia merawat bumi sebagai khalifah (Mardliyah, Sunardi, \& Agung, 2018), peduli lingkungan, serta memperlakukan hewan dengan baik. (Sarvestani \& Shahvali,, 2008); (Shaikh, 2018) Bahkan perilaku manusia terhadap air, udara dan tanaman pun diperhatikan dalam Islam. (Gul \& Ali, 2018) Tata cara umat Islam berperilaku terhadap lingkungannya ini dapat dirangkum dalam terminologi Islamic Environmental Ethics (Khalid, 2005)

Penelitian awal paper ini, diawali keprihatinan adanya gap antara pembelajaran matematika yang mengedepankan logika, dengan pengenalan nilai-nilai keislaman yang lebih pada ranah rasa maupun etika. Tulisan ini ingin mendorong terbukanya pemikiran bahwa: belajar matematika dapat pula untuk mengasah rasa dan mengenal Islam itu bisa pula melalui cinta alam dan lingkungan. Secara akademik dapat diistilahkan: belajar matematika tidak hanya sekedar mengedepankan logika saja, di sisi lain mengenal Islam tidak hanya tentang ritual ibadah saja. Sehingga harapannya diperoleh simbiosis mutualisme dua arah: dengan mencintai lingkungan, belajar matematika menjadi tidak menakutkan, dan mencintai lingkungan itu adalah amalan mulia dalam Islam. 
Bagaimana mendesain pembelajaran matematika di SD/MI, yang mensupport pada kepedulian lingkungan untuk mengenalkan nilai-nilai Islam, ini menjadi hal yang penting untuk didiskusikan. Menggunakan sumber belajar, dengan menyusun suplemen khusus dalam pembelajaran dapat dilakukan untuk tercapainya tujuan pembelajaran. (Reizal, H., Agustiningsih, A., \& Hutama, F. S. 2020). Untuk itu, pembahasan penyusunan Lembar Kerja untuk siswa berbasis kegiatan, yang melibatkan anggota keluarga di rumah yang menumbuhkan nilai-nilai positif kepedulian lingkungan sesuai nilai-nilai dalam Islam, akan disampaikan dalam paper ini.

\section{METODE}

Paper ini disusun berdasar penelitian literatur, dan penelitian pengembangan tahap awal. Tahap awal maksudnya, baru sampai 3 tahap dari kesepuluh tahap pengembangan Borg dan Gall. Tiga tahap tersebut meliputi: Mengetahui potensi dan masalah, mengumpulkan informasi, dan desain produk awal. Jadi baru sampai tahap desain belum sampai tahap uji validasi, ujicoba maupun diseminasi. Sumber data primer adalah artikel maupun penelitian terkait pembelajaran matematika SD/MI, nilai-nilai Islam tentang kepedulian lingkungan, etika lingkungan menurut Islam, pengembangan LKS atau LKPD, serta standar proses pendidikan nasional terutama Standar kompetensi dan kompetensi dasar kelas 1 SD. Sumber data sekunder adalah bacaan terkait integrasi nilai-nilai Islam dengan pembelajaran. Adapun langkah pengembangan yang sudah dilakukan adalah mengetahui potensi dan masalah pembelajaran matematika dan pengembangan suplemen pembelajaran, mengumpulkan informasi terkait Islamic Environmental Ethics dan kompetensi Dasar yang sesuai, lalu tahap desain produk awal. Desain produk awalnya berupa rancangan atau produk awal Lembar Kerja untuk siswa SD kelas 1 pada KD 3.2 dan KD 4.2

\section{HASIL DAN PEMBAHASAN Hasil}

\section{Potensi dan Masalah}

Pembelajaran matematika di SD/MI memungkinkan untuk selalu dikembangkan, divariasi dan dieksplorasi menuju perbaikan kualitasnya. Perbaikan kualitas dapat melalui peningkatan kompetensi guru, perbaikan proses pembelajarannya, peningkatan kualitas sarana prasarananya termasuk perangkat pembelajarannya, maupun medianya. Mengingat pentingnya kelestarian lingkungan dan sisi sebaliknya: terjadi kerusakan lingkungan dalam beberapa dekade terakhir maka pengembangan pembelajaran dengan mengintegrasikan kepedulian lingkungan menjadi kebutuhan yang perlu diakomodir. Sayangnya berdasar survei 100 guru MI seJateng-DIY, diperoleh hasil, pengetahuan para guru mengenai nilai-nilai Islamic Environmental Ethics termasuk kategori tinggi, yaitu lebih dari $80 \%$. Namun implementasi dan integrasi dalam pembelajaran masih sangat rendah yaitu kurang dari $30 \%$. Hal ini berarti masih ada potensi untuk mengembangkan pembelajaran yang menjadi solusi untuk meningkatkan adanya integrasi nilai-nilai etika lingkungan Islam dalam pembelajaran

Melihat potensi saratnya nilai-nilai Islam tentang kepedulian lingkungan, maka tidak akan terlalu sulit untuk menggali nilai-nilai tersebut, untuk ditampilkan dalam pembelajaran. Dengan berbekal pentingnya pengembangan pembelajaran yang konstruktif, sekaligus menyenangkan dalam pembelajaran matematika, maka perlu 
dipikirkan, bagaimana menyusun, menyelenggarakan pembelajaran matematika yang mengedukasi pentingnya kepedulian terhadap lingkungan hidup.

\section{Mengumpulkan Informasi}

Pada tahap ini, peneliti melakukan eksplorasi melalui inventarisir artikel, buku dan referensi mengenai Islamic Environmental Ethics, juga mengenai tema-tema pada kelas 1-6 yang terkait nomenklatur IEE. Selain itu, juga mengumpulkan referensi terkait pembelajaran matematika khususnya tentang peraga yang terkait lingkungan sekitar siswa, juga terkait model pembelajaran yang mendorong siswa lebih mudah memahami konsep. Hasilnya diperoleh 5 nilaiIEE yaitukepedulian Islam terhadap tanaman, hewan, air, udara dan bumi. Selain itu diperoleh KD 3.2 dan 4.2 pada kelas 1 untuk dikembangkan LKPD nya. Lembar kerja yanag disusun mengedepankan proses konstruktif agar siswa mampu menemukan pemahamannya sendiri.

\section{Desain Produk Awal}

\section{A.LKPD Matematika Berbasis Islamic Environmental Ethics}

LKPD disusun dengan disesuaikan usia peserta didik.Usia SD/MI masih dalam usia kongkret, artinya dalam belajar memerlukan peraga, media yang dapat dilihat, dipegang, digunakan dengan nyata. Lembar Kerja yang dirancang pada paper ini menggunakan peraga daun, batu dan biji-bijian dari lingkungan sekitar peserta didik. Penggunaan dedaunan pada paper ini, menjadi cara untuk mengenalkan manfaat tanaman atau bagian pada peserta didik.

Konsep Islamic Environmental Ethics memuat berbagai etika dan perilaku, bagaimana sebaiknya umat Islam memperlakukan air, udara, bumi, tanaman dan hewan. Konsep initentunya memuat teori dan praktek dari yang paling sederhana sampai yang paling kompleks. Untuk tingkat SD/MI, penggunaan peraga pembelajaran di lingkungan terdekat siswa, menjadi alternatif paling sederhana untuk mengenalkan konsep Islamic Environmental Ethics. Orang tua menjadi pemeran sentral dalam mengenalkan cinta lingkungan pada siswa. Hal ini dapat dimulai dengan menanam pohon, merawatnya, dan memanfaatkannya dengan secukupnya.

Pada Lembar Kerja yang dirancang ini, peneliti menggunakan batu, dedaunan: daun jambu air dan daun belimbing serta biji-bijian sebagai peraga/media belajar. Saat menggunakan peraga ini, guru maupun orangtua dapat menyisipkan pesan kepada peserta didik untuk menyukai menanam pohon dan memanfaatkannya dengan baik. Karena hal tersebut merupakan kebaikan yang disukai dan diperintahkan oleh Allah dan Rasul seperti pada QS. Al-An'am: 114 dan hadits menanam pohon (Mamat \& Mahamood, 2017); (Istianah, 2015) Dan rancangan lembar kerja ini akan dilengkapi dengan Panduan untuk Guru mengenai Pembelajaran Matematika Berbasis Islamic Environmental Ethics.

Lembar Kerja Matematika ini menyajikan aktifitas-aktifitas untuk mempelajari matematika. Jadi proses belajar peserta didik akan tidak membosankan, karena dilakukan dengan kegiatan sesuai usia anak. Hal ini juga sesuai dengan konsep matematika untuk anak, bahwa matematika untuk anak ada di sekitarnya, dapat dipelajari melalui berbagai kegiatan maupun permainan (Skinner \& Mahamood 2011)

\section{B.Komponen Lembar Kerja}

Komponen Lembar Kerja terdiri dari Kompetensi Dasar, Indikator, Ayat Alqur'an, Hadits, Gambar-gambar, Aktifitas-aktifitas, kolom SAFETY dan Motivasi. Satu persatu komponen akan dijelaskan dengan uraian sebagai berikut. 


\section{C.Kompetensi Dasar}

Muatan Kompetensi Dasar dipilih yang sesuai dengan basis Islamic Environmental Ethics. Ada dua kompetensi dasar yang digunakan yaitu sebagai berikut. Kompetensi Dasar 3.2: Menjelaskan bilangan sampai dua angka dan nilai tempat penyusun lambang bilangan menggunakan kumpulan benda konkret serta cara membacanya.

Kompetensi Dasar 4.2: Menuliskan lambang bilangan sampai dua angka yang menyatakan banyak anggota suatu kumpulan objek dengan ide nilai tempat.

\section{D.Indikator}

Komponen ini diisi dengan indikator yang diuraikan berdasar dua KD yang dipilih. Berdasar kompetensi dasar 3.2 dan 4.2 dapat disampaikan 5 indikator yang akan dicapai dalam pembelajaran menggunakan Lembar kerja yang disusun. Indikatorindikatornya adalah:

1. Siswa dapat menyebutkan satuan dari suatu bilangan

2. Siswa dapat menyebutkan puluhan dari suatu bilangan

3. Siswa dapat menyusun lambang bilangan dengan benda kongkret

4. Siswa dapat mengucapkan lambang bilangan dua angka yang menggunakan benda kongkret puluhan dan satuan

5. Siswa dapat menuliskan lambang bilangan yang ditunjukkan dengan menggunakan benda kongkret

\section{E.Ayat Qur'an}

Bagian ini diisi dengan ayat-ayat Alqur'an terkait komponen-komponen etika

Islam terhadap air, udara, bumi, hewan maupun tanaman. Pada rancangan

Lembar Kerja yang disusun ini, dipilih surah ar-Rahman ayat 68.

$$
\text { (YN) }
$$

Siswa diminta untuk menyebutkan terjemahannya/artinya dalam bahasa Indonesia

\section{F.Hadits}

Komponen ini diisi dengan hadits-hadits yang terkait Islamic Environmental Ethics, yaitu hadits yang berhubungan dengan etika dalam Islam terhadap air, udara, bumi, hewan maupun tanaman.

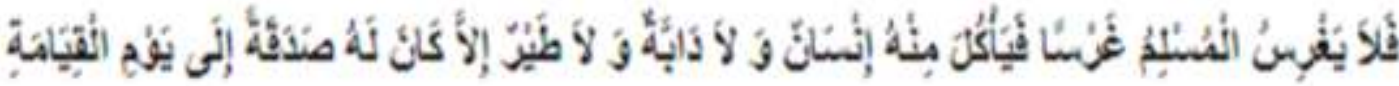

"Tidaklah seorang muslim menanam tanaman, lalu tanaman itu dimakan manusia, binatang atau burung, melainkan tanaman itu menjadi sedekah baginya sampai hari kiamat (HR Imam Muslim hadits no1552 (10) keluarga.

Dalam kegiatan membaca hadits, dilakukan dengan bimbingan anggota 


\section{G.Gambar-Gambar}

Gambar-gambar pada Lembar Kerja diisi dengan gambar peraga daun dan batu, yang disajikan secara konstruktif untuk menunjang kegiatan-kegiatan yang dilakukan oleh perserta didik. Gambar pada LKPD ini terdiri dari gambar 1 sampai dengan gambar 10

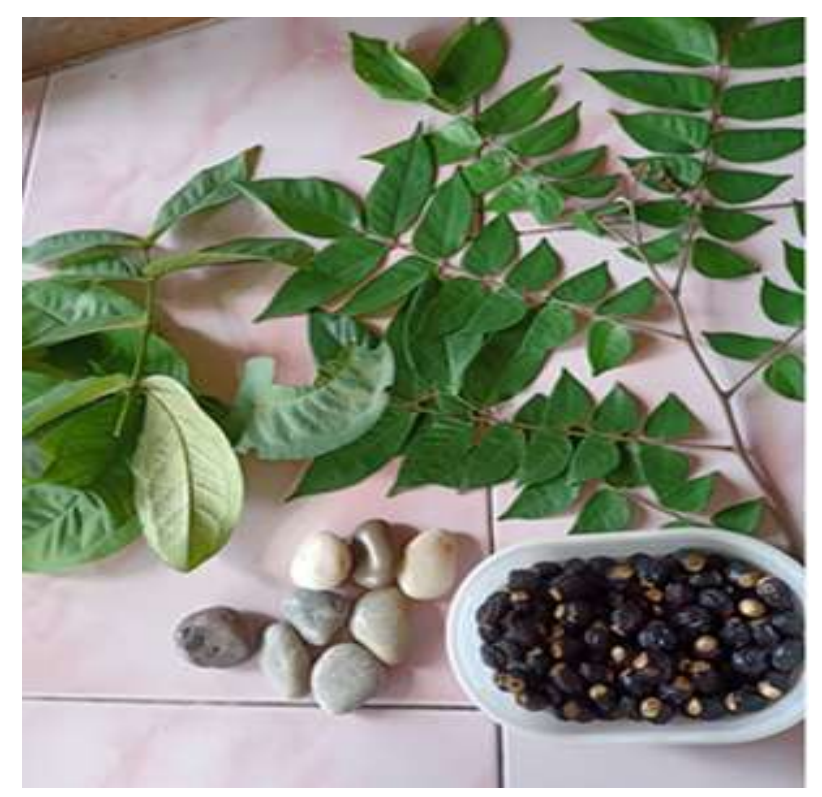

Gambar 1. Tampilan peraga daun, batu dan biji-bijian pada LKPD

Gambar susunan lambang bilangan menggunakan peraga kongkret yaitu batu dan daun, digunakan untuk membimbing peserta didik memahami nilai tempat satuan dan puluhan, dari yang sederhana sampai yang lengkap. Contoh yang sederhana adalah memuat satu komponen saja yaitu satuan saja (gambar 3) yang menyajikan tiga batu kecil adalah lambang dari bilangn 3. Kemudian contoh lambang puluhan saja (gambar 4) menyajikan satu batu besar yang melambangkan 1 puluhan atau bilangan 10

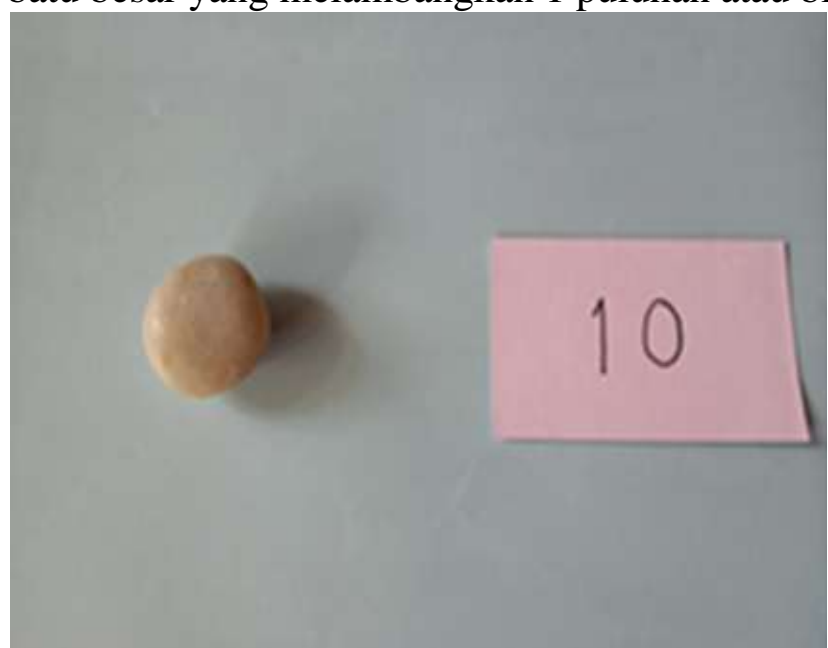

Gambar 2.Tampilan contoh gambar memuat satu komponen saja berupa puluhan menggunakan peraga batu

Contoh yang lengkap yaitu memuat satuan dan puluhan terdapat pada gambar 5, gambar 6 dan gambar 8. Pada gambar 5 di LKPD, nampak 2 daun besar dan satu daun kecil, yang menunjukkan lambang 2 puluhan dan 1 satuan atau bilangan 21 


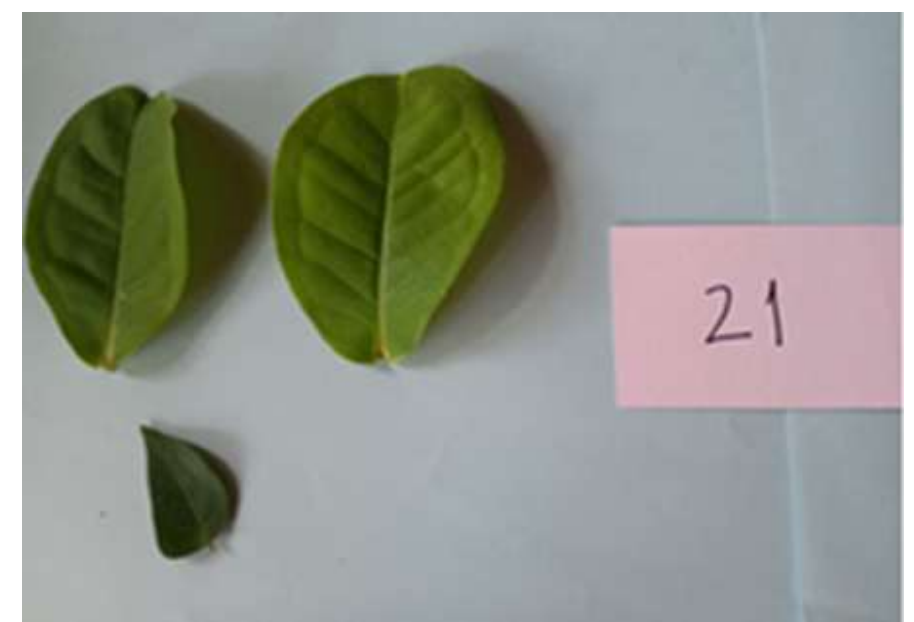

Gambar3.Tampilan contoh gambar lengkap puluhan dan satuan di LKPD menggunakan dedaunan

Setelah peserta didik memahami contoh penggunaan lambang satuan, puluhan dan gabungan dari puluhan dan satuan, kemudian Lembar Kerja mengajak peserta didik untuk berlatih menuliskan lambang bilangan. Gambar pada LKPD terletak di nomor gambar 9 dan 10

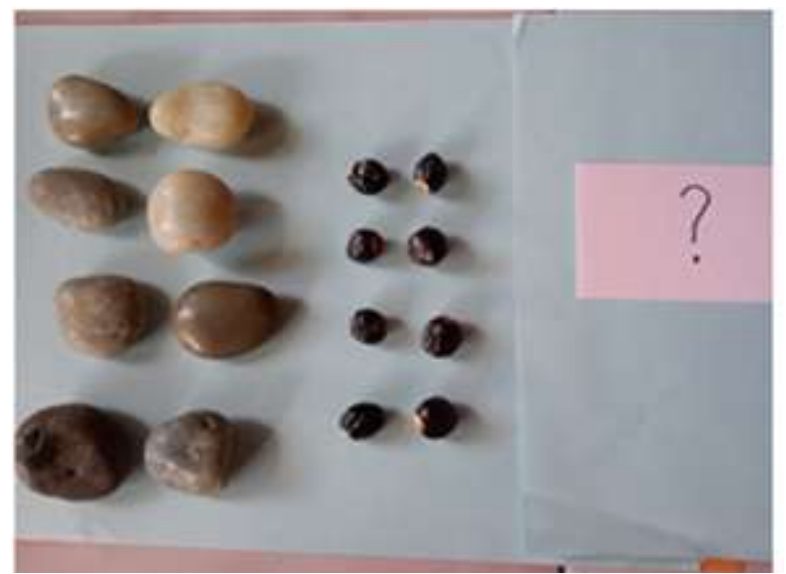

Gambar 4.Tampilan lambang bilangan lengkap dengan puluhan dan satuan di LKPD menggunakan peraga batu

Gambar 10 pada rancangan Lembar Kerja dari paper ini menampilkan gambar peraga kongkret berupa batu besar dan kecil, terdiri dari 8 batu besar dan 8 batu kecil. Bagian ini dimaksudkan untuk melatih peserta didik menuliskan lambang bilangan dua angka terdiri dari puluhan dan satuan.

\section{H.Aktivitas}

Aktifitas pada LKPD ini terdiri dari aktifitas1sampai dengan aktifitas 6. Pada aktifitas 1 dan 2, hanya berupa instruksi tanpa gambar yaitu agar peserta didik menyiapkan peraga berupa batu besar dan kecil, serta daun besar dan kecil sebanyak masing-masing 10 buah. Pada aktifitas 3, peserta didik melakukan investigasi mencari data umur keluarga, kemudian melakukan kegiatan menyusun peraga daun atau batu. Sedangkan aktifitas 4 yaitu peserta didik menuliskan lambang-lambang bilangan yang disajikan dengan peraga dalam gambar 3 sampai dengan gambar 8 pada LKPD. Aktifitas 5: terdiri dari dua aktifitas yaitu aktifitas A dan B. Dua aktifitas ini yaitu terdiri dari 2 kegiatan menyusun peraga kongkret untuk melambangkan bilangan terdiri dari dua angka. Aktifitas 6: langkah 1-5 terdiri dari gambar-gambar sebagai petunjuk 
aktifitas peserta didik dalam menentukan satuan dan puluhan dari peraga maupun dari bilangan yang ditentukan.

\section{I.Kolom Safety}

Kolom SAFETY: Memuat peringatan untuk orang tua atau guru agar memberikan pengawasan saat peserta didik menggunakan peraga batu maupun bijibijian. Komponen KOLOM SAFETY ini jarang, atau bahkan mungkin belum ada dalam LKPD selama ini. Padahal ini merupakan hal penting, agar dalam proses pembelajaran tidak terjadi hal-hal yang membahayakan.

\section{J.Kolom Motivasi}

Pada komponen ini, disampaikan pesan, nasehat atau motivasi bermuatan Islamic Environmental Ethics (IEE) yang sesuai dengan nilai IEE mana yang disampaikan berkaitan dengan KD dan indikator maupun peraga yang digunakan.

Pada rancangan LKPD di paper ini, kolom motivasi diisi dengan pesan menyayangi tanaman, karena nilai IEE yang disampaikan adalah terkait peraga dedaunan yang berasal dari tanaman. Dan isi motivasi juga terkait dengan ayat Alqur'an dan hadits yang disampaikan di Lembar Kerja bagian awal.

\section{Nilai-Nilai Islamic Environmental Ethics}

\section{Pembahasan}

Islam adalah agama yang sangat memperhatikan kelestarian lingkungan (Matin, 2010); (Killawi, 2014) Dalam Alqur'an dan hadits banyak ditegaskan kaidah-kaidah, aturan-aturan, bagaimana cara memperlakukan alam lingkungan secara baik (Harahap, 2015); (Mauluah, 2017))

Istilah Islamic Environtmental Ethics mulai dipergunakan oleh Samarrai tahun 1990 pada artikelnya yang berjudul: Islamic Environmental Ethics, Law, and Society Ethics of Environment and Development. (Gottlieb, 2004) dan oleh Fazlun Khalid pada buku Richard C. Foltz (Editor) berjudul Environmentalism in the Muslim World; (Khalid, 2005) Prinsip-prinsip IEE pada paper ini, adalah khusus meliputi cara memperlakukan air, hewan, tanaman, bumi, dan udara (Manoiu et al, 2016)

a.Islamic Environmental Ethics tentang air

Alqur'an menjelaskan kegunaan air sebagai sumber kehidupan dalam surat 21:30, 25:54, 24:45 (Santoso, 2014) Selain itu, perhatian yang besar dari Islam terhadap pentingnya sumber daya air dan perangkatnya berupa sungai dan sebagainya, terlihat pada banyaknya penyebutan istilah air (maa'), sungai dan sungai-sungai (nahr dan anhar), air minum sebanyak masing-masing 63, 54, dan 39 kali di dalam Alqur'an .(Naff, 2009)

\section{b.Islamic Environmental Ethics tentang hewan}

Alqur'an juga memberi perhatian yang tinggi dalam mengingatkan umatnya atas kesadaran pada penciptaan hewan untuk kemanfaatan manusia. Hal tersebut tercantum dalam beberapa ayat sebagai berikut. QS. 16 (An Nahl) ayat 5: Hewan ternak untuk dimakan dan dimanfaatkan bulunya. QS.16 (An Nahl) ayat 7: hewan digunakan untuk mengangkat beban; Ayat 8: kuda, bagal dan keledai untuk tunggangan dan perhiasan; QS 22 (Al-Hajj): unta untuk makanan dan sodakoh. (Rahman, 2017)

\section{c.Islamic Environmental Ethics tentang tanaman}

Perhatian Islam atas hubungan manusia dengan tanaman, tertulis dalam Alqur'an QS An-Nahl: 114 (Mamat \& Mahamood, 2017), misalnya pentingnya memanfaatkan tanaman tanpa berlebihan. Pentingnya menanam pohon, konsep menanam pohon adalah sodakoh (jika ada hewan maupun manusia memanfaatkannya), dilarang memotong 
pohon tanpa alasan tertentu; diperintahkan oleh Nabi dalam haditsnya. (Ali \& Gul, 2018)

\section{d.Islamic Environmental Ethics tentang bumi}

Islam menugaskan manusia sebagai khalifah fil-ard (wakil Tuhan di bumi). Makna sebagai wakil Tuhan,Tuhan yang Maha Pengasih, Penyayang, dan pemilik 99 asmaul husna, maka tentu saja merupakan tugas tidak ringan yang dan penuh kehormatan, tugas kekhalifahan itu. Penyebutan manusia sebagai khalifah fil-ard ini sudah menunjukkan kepedulian Islam terhadap kelestarian kehidupan di bumi. (Mardliyah et al, 2018) Penyebutan khalifah fil-ard dalam Alqur'an antara lain pada: (QS. Al- Baqarah [2] : 30), yang mana jika beriman dan beramal saleh, maka Tuhan akan menjadikan manusia sebagai penguasa bumi. (Q.S. An-Nur [24]: 55). Secara garis besar, ayat-ayat tersebut menunjukkan tanggungjawab manusia adalah menjaga bumi seisinya. Hal itu juga seperti sesuai ayat dalam Q.S. Al-An"am:165) (Iqbal, 2016)

Makna khalifah fil-ard ini mempunyai makna yang luas, antara lain: tugas mulia manusia adalah memakmurkan bumi, termasuk dalam dimensi sosial serta kepeduliannya terhadap lingkungan secara material (Safei, 2016) Fungsi bumi yang sangat vital, sebagai tempat seluruh makhluk bernaung, menjadi bahasan penting dalam Qur'an. Bumi, sebagai tempat tumbuhnya segala tanaman, juga perlu dirawat, asalkan manusia tidak berlebih-lebihan/melampaui batas (QS 16:11) ; Bumi adalah tempat lahir dan mati manusia tertulis dalam kitab Qur'an: 71:17-18, Bumi sebagai hamparan, agar manusia dapat bepergian mengelilinginya,terdapat dalam QS 71:19-20 (Manoiu et al, 2016)

\section{e.Islamic Environmental Ethics tentang udara}

Etika lingkungan dalam Islam tentang udara, ada hubungannya dengan pentingnya manusia menjaga kelestarian air. Ketersediaan air adalah terkait dengan lancarnya proses siklus air (Bellette \& Lee , 2003). Hal ini disampaikan dalam Qur'an QS 56: 68-70. Setelah itu, bagaimana Tuhan mengirim angin (udara) ke daerah-daerah tandus untuk menjadikannya hujan, juga tertulis dalam Qur'an, yaitu: QS 7:57 (Manoiu et al, 2016)

\section{Lembar Kerja yang Terintegrasi dengan Nilai-Nilai Islam}

Nilai-nilai Islam dalam kehidupan, tidak akan lekang oleh perkembangan jaman. Mengingat hal ini, sudah selayaknya umat pemeluknya, dalam proses pendidikan senantiasa mengeksplornya untuk mendorong pengamalannya dalam berbagai bidang. Dalam pengembangan bahan ajar, buku dan lembar kerja, banyak peneliti, guru dan praktisi pendidikan yang telah menggunakan, mengintegrasikan nilai-nilai Islam di dalamnya. Hal ini khususnya untuk sekolah Islam atau madrasah, dimaksudkan agar bahan ajarnya mempunyai ciri khas bermuatan nilai -nilai Islam. (Jannah, R, 2016). Berdasar berbagai penelitian, telah terbukti bahwa pembelajaran yang terintegrasi dengan nilai Islam dengan model tertentu dapat mendorong kualitas pembelajarannya. Di bidang IPA terbukti menyokong terbentuknya siswa yang beriman dan bertaqwa (Muspiroh, 2014) Dalam pembelajaran matematika, menggunakan memodifikasi model pembelajaran Gerlach dan Ely melalui integrasi nilai-nilai keislaman ternyata dapat meningkatkan kemampuan representasi matematis. (Yustina, Maskur \& Suherman, 2016).

Saat proses pembelajaran, kadang ditemui bahwa penggunaan buku siswa saja tidak cukup untuk memenuhi ketercapaian tujuan pembelajaran, jadi guru perlu mengembangkan suplemen khusus untuk pembelajaran. (Reizal, Agustiningsih \& Hutama, 2020) Dalam melaksanakan pembelajaran, Lembar Kerja sangat strategis 
untuk digunakan dalam mencapai tujuan pembelajaran. (Amirulloh, S., Carlian, H. Y., \& Rohmah, S.K. 2020). Desain LKPD yang terintegrasi dengan model pembelajaran tertentu dapat digunakan pada berbagai mata pelajaran dan memberikan kemanfaatan dalam meningkatkan kualitas pembelajaran. Banyak manfaat yang diperoleh dari penggunaan LKPD yang teritegrasi nilai-nilai Islam. Pembelajaran IPA yang terintegrasi nilai Islam dengan inkuiri terbimbing mencapai kategori sangat menarik menurut peserta didik, sebesar 90\% (Latifah, 2016) Pembelajaran matematika menggunakan LKPD Matematika trigonometri terintegrasi nilai Islam dengan inkuiri terbimbing menghasilkan pembelajaran yang sangat-sangat menarik (Syarifah,S 2017) Pembelajaran matematika menggunakan LKPD Matematika dengan discovery learning memuat nilai-nilai Islam efektif meningkatkan hasil belajar (Safitri, Hanifah \& Rusdi 2020) Adapun untuk peserta didik di tingkat SD/MI, diperoleh hasil yaitu pembelajaran matematika dengan LKPD Matematika untuk tingkat SD menggunakan PBL efektif sebesar $85 \%$ dalam memperoleh capaian pembelajarannya (Anggraini, F., Kusnadi, K., \& Alfiah, A., 2019).

\section{Pembelajaran Matematika Berbasis Aktifitas yang Konstruktif}

Pendekatan konstruktivisme merupakan cara pembelajaran yang menjelaskan bagaimana pengetahuan dapat disusun dalam pikiran siswa. (Mauluah, 2009) Pembelajaran yang konstruktif adalah pembelajaran yang berupaya memfasilitasi siswa untuk membangun pengetahuan, melalui kegiatan yang memberi pengalaman. Pengalaman diperoleh melalui pengamatan dan interaksi dengan lingkungan. (Yulianti \& Herpratiri, 2019) Pembelajaran dengan pendekatan konstruktivisme terbukti dapat meningkatkan pencapaian hasil belajar matematika (Mehar \& Sanwal, 2017) Implementasi pendekatan konstruktivisme, dapat dilaksakan melalui pembelajaran dengan prinsip PAKEM (Mauluah, 2009) Lembar kerja yang disusun pada paper ini juga memuat pembelajaran yang aktif, kreatif dan menyenangkan karena menampilkan kegiatan-kegiatan pada setiap langkahnya, sehingga peserta didik yang menggunakannya akan terlibat aktif dalam proses mengonstruksi pengetahuannya. Seperti yang disampaikan Yulianti dan Herpratiri (Yulianti \& Herpratiri, 2019) pendekatan konstruktivisme dapat dilakukan melalui kegiatan yang memberi pengalaman belajar bermakna pada siswa. Artinya perlu disusun kegiatan atau aktifitas tertentu yang mengarahkan peserta didik untuk menemukan konsep yang akan dicapai dalam tujuan pembelajaran.Jika prosedur konstruktivisme didesain dengan baik, maka pembelajaran yang konstruktif akan memberikan kebermaknaan bagi tercapainya tujuan pembelajaran.

Celik (Celik, 2018) menjelaskan bahwa pembelajaran berbasis aktifitas terbukti meningkatkan prestasi akademik dan attitude. Aktifitas yang telah dilakukan dalam praktek pembelajaran integer ialah dengan menggambar garis bilangan, menghitung piring dan menggambar tangga. Menurut Festus (Festus, 2013): pembelajaran matematika dengan aktifitas terdiri dari 4 aspek yaitu dengan pengajaran discovery, dengan praktek yang sesuai, menggunakan peraga, dan cooperative atau kerja kelompok. Pada paper ini, dari 4 langkah tersebut, ada 3 yang dilakukan yaitu menemukan sendiri melalui langkah-langkah sistematis konstruktif pada LKPD, melakukan aktifitas praktek yaitu dengan menyusun peraga satuan dan puluhan, menyebutkan bilangan dua angka-nya dengan menuliskan lambang bilangannya, dan menggunakan peraga. 


\section{PENUTUP}

Menyelenggarakan pembelajaran matematika yang bermakna dan menyenangkan, selalu menjadi hal yang diidam-idamkan oleh semua pendidik di bidang matematika. Untuk institusi SD Islam maupun Madrasah Ibtidaiyah, melaksanakan pembelajaran matematika yang mempromosikan nilai-nilai Islam menjadi tantangan tersendiri. Dari beberapa penelitian, dengan menggunakan model pembelajaran yang sesuai, pembelajaran matematika yang mengintegrasikan nilai-nilai Islam banyak memberi manfaat antara lain: pembelajaran menjadi sangat menarik, efektif untuk capaian pembelajaran, juga dapat meningkatkan prestasi belajar dan attitude yang baik. Lembar Kerja pada paper ini memberikan contoh integrasi dengan menyajikan ayat Alqur'an QS.Ar-Rahman: 68 dan hadits terkait Islamic Environmental Ethics berkaitan dengan etika terhadap tanaman yaitu keutamaan menanam pohon sebagai sedekah. Kompetensi yang dapat diintegrasikan dengan IEE adalah KD 3.2 dan 4.2. Manfaat yang dapat diambil oleh siswa adalah mendapatkan langkah-langkah pembelajaran yang konstruktif sekaligus mengenal tanaman dan menyayangi tanaman untuk dimanfaatkan sebagai peraga pembelajaran matematika. Juga dapat menghargai lingkungan sekitarnya yaitu dengan memanfaatkan bebatuan dan biji-bijian untuk pembelajaran. Rancangan LKPD ini belum mendapat validasi dari para ahli, sehingga sangat terbuka untuk mendapat masukan yang melanjutkan penelitian ini menjadi penelitian/paper baru terkait LKPD terintegrasi nilai-nilai Islam tentang kepedulian lingkungan.

\section{UCAPAN TERIMA KASIH}

Penulis menyampaikan terima kasih kepada MORA Scholarship/Beasiswa Kemenag 5000 Doktor 2017 untuk studi lanjut S3. Sehingga penulis dapat melaksanakan penelitian ini.

\section{DAFTAR PUSTAKA}

Abdullah. (2021). Multidisiplin, Interdisiplin dan Transdisiplin Ilmu Pengetahuan dan Riset pada Perguruan Tinggi Masa Pandemi. Prosiding Konferensi Integrasi Interkoneksi Islam Dan Sains.ISSN 1535697734Volume 3 Februari 2021

Amirulloh, S., Carlian, H. Y., \& Rohmah, S. K. (2020). Kemampuan Berpikir Kreatif Matematis Siswa Melalui Penggunaan Strategi Mathematical Bet

Line. Muallimuna: Jurnal Madrasah Ibtidaiyah, 5(2), 85-94.

Anggraini. (2019). Pengembangan Lembar Kerja Peserta Didik (Lkpd) Matematis Berbasis Pbl Terintegrasi Nilai-Nilai Islam di Sekolah Dasar Islam Terpadu. JMIE (Journal of Madrasah Ibtidaiyah Education), 3(2), 168-178.

Bellette. (2003). (editor); NT Waterwatch Education Kit. Part 1: The Water Cycle and Water Properties. Published by Department of Infrastructure, Planning and Environment (DIPE) PO Box 30 Palmerston NT

Calkins. (2020). Using Peer-Assisted Reflection in Math to Foster Critical Thinking and Communication Skills. PRIMUS, 30(4), 475-499. Retrieved from https://www.tandfonline.com/doi/abs/10.1080/10511970.2019.1608608

Celik. (2018). The effects of activity based learning on sixth grade students' achievement and attitudes towards mathematics activities. EURASIA Journal of Mathematics, Science and Technology Education, 14(5), 1963-1977.

Constanza. (2014). Changes in the global value of ecosystem services. Global Environmental Change 26:152-158.

Festus. (2013). Activity-based learning strategies in the mathematics classrooms. Journal of Education and Practice, 4(13), 8-14. 
Garcia. (2017). Math worksheet and form generator for teaching 7th grade students. Retrieved from http://csus-dspace.calstate.edu/handle/10211.3/190810

Gottlieb. (2004). This sacred earth: Religion, nature, environment. Second Edition.Published in 2004 by Routledge 29 West 35th Street New York, NY $10001 \mathrm{http}: / /$ www.routledge-ny.com/

Gul. (2018). An Islamic approach towards environmental protection; Journal of Law andSociety Law College Vol. XLIX, No. 73 University of Peshawar July 2018

Harahap. (2015). Etika Islam dalam mengelola lingkungan hidup; Jurnal EduTech Vol 1 No 1 Maret 2015

Iqbal. (2016). Mewujudkan kesadaran energi melalui konsep khalifah $\mathrm{Fi}$ al'Ard. JURNAL PENELITIAN, 187-200.

Istianah. (2015). Pengembangan Media Flashcard Berpendekatan PRAMEK Tema Energi Pada Makhluk Hidup untuk Siswa SMP. Unnes Science Education Journal, 4(1).

Jannah, R. (2016). Pengembangan Buku Ajar Tematik Bernuansa Islami untuk Madrasah Ibtidaiyah/Sekolah Dasar Islam. Muallimuna, 2(1), 1-16.

Keyes. (2004). The post truth era-dishonesty and deciption in contemporary life. W.W Norton \& Company.Inc

Khalid. (2005). Applying Islamic Environmental Ethics; in Richard C. Foltz (Editor); Environmentalism in the Muslim World; Nova Science, New York, 2005 http://www.ifees.org.uk/wp-content/uploads/2015/04/1379668914.pdf

Kholil. (2019). Pengembangan Buku Ajar Matematika Terintegrasi Nilai-Nilai Keislaman dalam Penanaman Karakter Siswa Madrasah Ibtidaiyah. Madrasah: Jurnal Pendidikan dan Pembelajaran Dasar, 12(1), 52-62.

Killawi, R. L. (2014). Sustainable Development From Islamic Perspective. 72. Dubai

Latifah. (2016). Pengembangan lembar kerja peserta didik (LKPD) berorientasi nilainilai agama Islam melalui pendekatan inkuiri terbimbing pada materi suhu dan kalor. Jurnal Ilmiah Pendidikan Fisika Al-Biruni, 5(1), 43-51.

Mamat. (2017). Islamic Philosophy on Behaviour-Based Environmental Attitude; Asian Journal of Environmen-Behaviour Studies, ajE-Bs, 2(2), Jan / Mar 2017 (p.81-91)

Manoiu. (2016). A qualitative exploration of the holy Alqur'an's environmental teachings; IJAEDU- International E-Journal of Advances in Education, Vol. 2, Issue 5, August 2016

Mardliyah, W., Sunardi, S., \& Agung, L. . (2018). Peran Manusia Sebagai Khalifah Allah di Muka Bumi: Perspektif Ekologis dalam Ajaran Islam. Jurnal Penelitian, 12(2), 355-378

Maskur. (2020). Pengembangan Bahan Ajar Matematika Berbasis Rhythm Reading Vocal pada Materi Konsep Pecahan Kelas VII SMP. Kreano, Jurnal Matematika Kreatif-Inovatif, 11(1), 78-87. Retrieved from https://journal.unnes.ac.id/nju/index.php/kreano/article/view/23562

Matin. (2010). Green Deen: What Islam teaches about protecting the planet. BerrettKoehler Publishers. 2010

Mauluah, L. (2009). Implementasi Pendekatan Konstruktivisme pada Pembelajaran Operasi Bilangan Bulat Di PGMI. Al-Bidayah: Jurnal Pendidikan Dasar Islam, 1(1).

Mauluah, L. (2017). Rancangan Pembelajaran Tematik Terpadu Matematika dan Mata Pelajaran Lain di SD/MI Kelas 1 Berdasar Konsep Islam Sebagai Agama Hijau; 
AL-BIDAYAH: Jurnal Pendidikan Dasar Islam Volume 9, Nomor 1, Juni 2017; ISSN: 2085-0034

Mehar. (2017). Effect of Constructive Learning Approach on Achievement in Mathematics in Relation to Self-efficacy. Educational Quest, 8, 343.

Melvinasari. (2019). Telaah Bahan Ajar Matematika Berbasis Realistic Mathematics Education untuk Meningkatkan Kemampuan Berpikir Logis Siswa SMP Kelas VII. In Seminar Nasional Pendidikan Matematika Ahmad Dahlan (Vol. 6).

Murtikusuma. (2019). Collaborative learning and caring community in mathematics learning by using student's worksheet based on scientific approach. In Journal of Physics: Conference Series (Vol. 1211, No. 1, p. 012108). IOP Publishing

Muspiroh. (2014). Integrasi nilai-nilai islam dalam pembelajaran IPA di sekolah. Quality, 2(1), 168-188.

Naff. (2009). Islamic Law and the Politics of Water. In Joseph W. Dellapenna \& Joyeeta Gupta (Eds.). The Evolution of the Law and Politics of Water (hlm. 3752). Dordrecht: Springer Science + Business Media B.V.

Rahman. (2017). : Religion and Animal Welfare: an Islamic Perspective. Animals 2017, 7, 11; doi:10.3390/ani7020011 Retrieved from www.mdpi.com/journal/animals

Reizal. (2020). Pengembangan Buku Ajar Berbasis Infografis Pada Tema Ekosistem Untuk Meningkatkan Hasil Belajar Siswa Kelas V SD. Muallimuna: Jurnal Madrasah Ibtidaiyah, 5(2), 54-65.

Safei. (2016). Islam and socio-ecological problems: How religion works in regard to earth theology. Man In India, 96(8), 2493-2502.

Safitri. (2020). Pengembangan Lembar Kerja Peserta Didik Menggunakan Model Discovery Learning Yang Terintegrasi Nilai-Nilai Islam Pada Materi Lingkaran Di Kelas Viii Smp Negeri 12 Kota Bengkulu (Doctoral dissertation, Universitas Bengkulu).

Santoso. (2014). Jurnal TARJIH, Air dan Pemeliharaannya dalam Perspektif Islam Volume 12 (1) $1435 \mathrm{H} / 2014 \mathrm{M}$

Sarvestani. (2008). Environmental Ethics: Toward an Islamic Perspective; AmericanEurasian J. Agric. \& Environ. Sci., 3 (4): 609-617, 2008, ISSN 1818-6769

Shaikh. (2018). Exploring the Significance of Islamic Environmental Ethics for Fostering Sustainable Environment; Journal of Islamic Banking and Finance Jan Mar 2018; Volume 35 Jan - Mar 2018 No. 1

Skinner. (2011). Maths is everywhere. children, 20(8942), 2826.

Syarifah. (2017). Pengembangan Lembar Kerja Peserta Didik (LKPD) Berorientasi Nilai-Nilai Agama Islam Melalui Pendekatan Inkuiri Terbimbing Materi Trigonometri

Yulianti. (2019). Pengembangan Media Pembelajaran IPA Berbasis Strategi Pembelajaran Konstruktif Sesuai dengan Karakteristik Lingkungan Guna Meminimalkan Terjadinya Miskonsepsi.

Yustina. (2016). Modifikasi model pembelajaran Gerlach dan Ely melalui integrasi nilai-nilai keislaman sebagai upaya meningkatkan kemampuan representasi matematis. Al-Jabar: Jurnal Pendidikan Matematika, 7(1), 29-38. 